\title{
High-Performance Li-ion Batteries and Super- capacitors Based on Prospective 1-D Nanomaterials
}

\author{
Dandan Zhao ${ }^{1,2}$, Ying Wang ${ }^{1}$, Yafei Zhang ${ }^{1 *}$
}

(Received 14 Nov. 2010; accepted 16 Mar. 2011; published online 30 April 2011.)

\begin{abstract}
One-dimensional (1-D) nanomaterials with superior specific capacity, higher rate capability, better cycling peroperties have demonstrated significant advantages for high-performance Li-ion batteries and supercapacitors. This review describes some recent developments on the rechargeable electrodes by using 1-D nanomaterials (such as $\mathrm{LiMn}_{2} \mathrm{O}_{4}$ nanowires, carbon nanofibers, $\mathrm{NiMoO}_{4} \cdot n \mathrm{H}_{2} \mathrm{O}$ nanorods, $\mathrm{V}_{2} \mathrm{O}_{5}$ nanoribbons, carbon nanotubes, etc.). New preparation methods and superior electrochemical properties of the 1-D nanomaterials including carbon nanotube (CNT), some oxides, transition metal compounds and polymers, and their composites are emphatically introduced. The $\mathrm{VGCF} / \mathrm{LiFePO}_{4} / \mathrm{C}$ triaxial nanowire cathodes for Li-ion battery present a positive cycling performance without any degradation in almost theoretical capacity (160 mAh/g). The Si nanowire anodes for Li-ion battery show the highest known theoretical charge capacity (4277 mAh/g), that is about 11 times lager than that of the commercial graphite $(\sim 372 \mathrm{mAh} / \mathrm{g})$. The SWCNT/Ni foam electrodes for supercapacitor display small equivalent series resistance (ESR, $52 \mathrm{~m} \Omega$ ) and impressive high power density $(20 \mathrm{~kW} / \mathrm{kg})$. The advantages and challenges associated with the application of these materials for energy conversion and storage devices are highlighted.
\end{abstract}

Keywords: One-dimensional nanomaterials; Li-ion battery; Supercapacitor; Electrochemical property

Citation: Dandan Zhao, Ying Wang and Yafei Zhang, "High-performance Li-ion batteries and Supercapacitors Based on Prospective 1-D Nanomaterials", Nano-Micro Lett. 3 (1), 62-71 (2011). http://dx.doi.org/ 10.3786/nml.v3i1.p62-71

\section{Introduction}

The greatest challenges in the twenty-first century are unquestionably global warming and the finite nature of fossil fuels. In order to meet the needs of modern society and in response to emerging ecological concerns, it is now essential to find and develop rapidly new, low-cost and environmentally friendly energy conversion and storage systems. Battery systems, which are the core components of mobile electric devices, have undergone significant improvements over the past 30 years [1]. Rechargeable Li-ion battery with high energy density, high working potential and long cycling life has been considered as one of the most promising power sources of portable systems and electric vehicles. Supercapacitors, which are promising auxiliary power sources for hybrid electric vehicles, have raised considerable attention over the past decade due to high power density and long cycle life compared to secondary batteries and high energy density vis-a-vis electrical double-layer capacitors [2]. The performance of these electrochemical energy conversion and storage devices depends intimately on the proper-

\footnotetext{
${ }^{1}$ Key Laboratory for Thin Film and Microfabrication Technology of the Ministry of Education, Research Institute of Micro/Nanometer Science and Technology, Shanghai Jiao Tong University, Shanghai 200240, China

${ }^{2}$ Key Laboratory of Nonferrous Metal Chemistry and Resources Utilization of Gansu Province, College of Chemistry and Chemical Engineering, Lanzhou University, Lanzhou 730000, China

*Corresponding author. Tel.: +86-21-34205665; Fax: +86-21-34205665; E-mail:yfzhang@sjtu.edu.cn
} 
ties of their active electrode materials. Nanomaterials have attracted great interest in recent years because of the unusual mechanical, electrical and optical properties due to the combination of bulk and surface properties to the overall behaviour [3]. Among the various nanomaterials, 1-D nanomaterials (nanowires [4], nanofibers, nanorods, nanoribbons, and nanotubes [5]) are attractive because of their small dimension structure, high aspect ratio, and unique device function. To date, many synthetic strategies, such as solution or vapor-phase approaches, solvothermal syntheses, self- assembly methods, template-directed methods, electrospinning techniques, etc., have been developed to fabricate 1-D nanomaterials. The 1-D nanomaterials have been proven to be efficient in electrochemical energy conversion and storage devices partially because of their unique physical and chemical properties. In this review, we focus on the preparation and application of 1-D nanomaterials for rechargeable Li-ion battery and supercapacitor. Figure 1 show typical morphologies of different 1-D nanomaterial in references we cited.
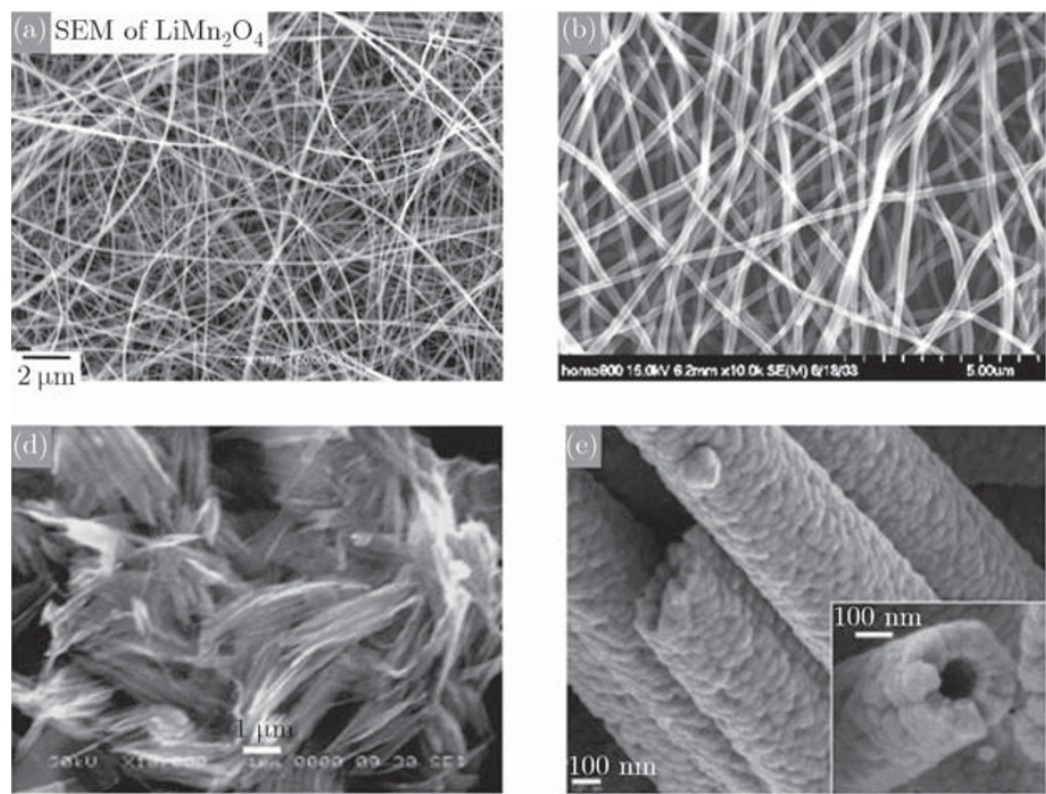
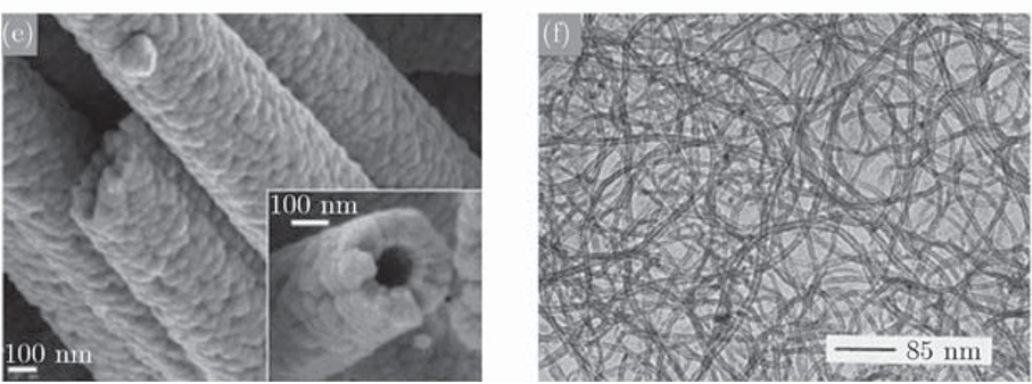

Fig. 1 Different 1-D nanomaterial morphologies: SEM images of (a) $\mathrm{LiMn}_{2} \mathrm{O}_{4}$ nanowires (from Ref. [7]), (b) carbon nanofibers (from Ref. [45]), (c) $\mathrm{NiMoO}_{4} \cdot n \mathrm{H}_{2} \mathrm{O}$ nanorods (from Ref. [16]), (d) $\mathrm{V}_{2} \mathrm{O}_{5}$ nanoribbons (from Ref. [14]), and (e) $\mathrm{Co}_{3} \mathrm{O}_{4}$ nanotubes (from Ref. [23]); and (f) TEM micrograph of carbon nanotubes (from Ref. [29]).

\section{Review of recent research}

\section{Application of 1-D nanomaterials in rechargeable Li-ion battery}

Li-ion batteries, which use $\mathrm{Li}^{+}$to transport charge between electrodes, are promising for rechargeable chemical energy storage due to the high mobility and energy density of $\mathrm{Li}^{+}$. Lithium also has a large negative reduction potential $\left(E^{0}=-3.05 \mathrm{~V}\right)$ which can produce a high-voltage output. A Li-ion battery consists of a Li-ion intercalation negative electrode (generally graphite), and a Li-ion intercalation positive electrode (generally the lithium metal oxide), these being separated by a Li-ion conducting electrolyte. Figure 2 is a schematic illustration of the Li-ion battery. As to Li-ion batteries, it is believed that the limitation in the rate capabilities is caused by the slow solidstate diffusion of $\mathrm{Li}^{+}$ions within the electrode

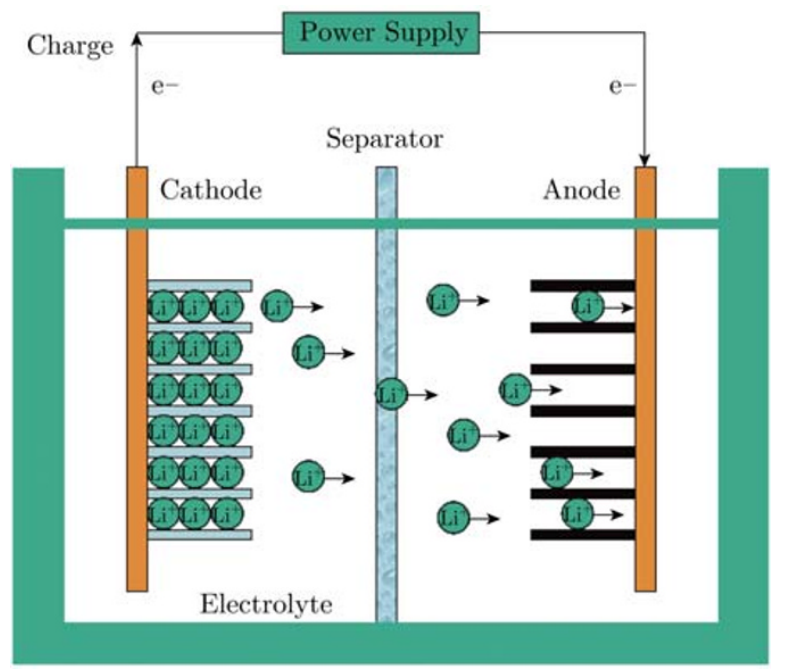

Fig. 2 Schematic illustration of a Li-ion battery. 
materials. The 1-D nanomaterials could be used in rechargeable Li-ion battery to achieve a fast solidstate diffusion due to the short diffusion distance of $\mathrm{Li}^{+}$ions.

\section{1-D Cathode materials}

Among the Li-ion battery materials, $\mathrm{LiCoO}_{2}$ has already been commercialized as a cathode material due to its high specific energy density and excellent cycle life. 1-D transition metal oxides with layered structures are attractive as cathode materials because of their ability to intercalate ions in a wide range of sites. $\mathrm{Gu}$ et al. prepared polycrystalline $\mathrm{LiCoO}_{2}$ fibers by the sol-gel assisted electrospinning technique. The $\mathrm{LiCoO}_{2}$ fibers as cathode materials offer a higher initial discharge capacity of $182 \mathrm{mAh} / \mathrm{g}$ compared with ca. $140 \mathrm{mAh} / \mathrm{g}$ of conventional powder and film electrodes [6]. The spinel $\mathrm{LiMn}_{2} \mathrm{O}_{4}$ is a low-cost, nontoxic, and highly abundant cathode material for Li-ion battery. Hosono et al. synthesized single crystalline cubic spinel $\mathrm{LiMn}_{2} \mathrm{O}_{4}$ nanowires using $\mathrm{Na}_{0.44} \mathrm{MnO}_{2}$ nanowires as a self-template. As cathode materials, $\mathrm{LiMn}_{2} \mathrm{O}_{4}$ nanowires show higher specific capacity, better high-rate capability and cycle stability than comparable nanoparticles [7]. Yang et al. obtained single-crystalline $\mathrm{LiMn}_{2} \mathrm{O}_{4}$ and $\mathrm{Al}$-doped $\mathrm{LiMn}_{2} \mathrm{O}_{4}$ nanorods by a two-step method that combines hydrothermal synthesis of single-crystalline $\beta-\mathrm{MnO}_{2}$ nanorods and a solid state reaction to convert them to $\mathrm{LiMn}_{2} \mathrm{O}_{4}$ nanorods. $\mathrm{LiMn}_{2} \mathrm{O}_{4}$ nanorods have a high charge storage capacity at high power rates compared with commercially available powders. Al dopants reduce the dissolution of $\mathrm{Mn}^{3+}$ ions significantly and make the $\mathrm{Al}$-doped $\mathrm{LiMn}_{2} \mathrm{O}_{4}$ nanorods much more stable than $\mathrm{LiMn}_{2} \mathrm{O}_{4}$ in Li-ion cycling performance tests [8]. Phospho-olivine $\mathrm{LiFePO}_{4}$ phase with the optimization of the environmentally benign and low-cost displays a theoretical capacity of $170 \mathrm{mAh} / \mathrm{g}$ [9]. Hosono et al. synthesized a triaxial $\mathrm{LiFePO}_{4}$ nanowire with a vapor-grown carbon fiber (VGCF) core and an amorphous carbon shell by the electrospinning method. The carbon fiber core oriented in the direction of the wire plays an important role in the conduction of electrons, whereas the outer amorphous carbon shell suppresses the oxidation of $\mathrm{Fe}^{2+}$ [10]. Murugan et al. used a microwave irradiated solvothermal method to prepare single crystalline lithium metal phosphates $\mathrm{LiMPO}_{4}(\mathrm{M}=\mathrm{Mn}, \mathrm{Fe}, \mathrm{Co}$, and $\mathrm{Ni})$ with nano-thumblike shapes. The lithium diffusion along the shorter dimension is particularly beneficial to achieve high-power capability. They also prepared $\mathrm{LiMPO}_{4} /$ multi-walled carbon nanotube (MWCNT) nanocomposites by a simple solutionbased mixing method to overcome the electronic conductivity limitations [11].

The 1-D cathode nanomaterials have the advantages of accommodating volume changes and supporting high rates. Sun et al. synthesized vanadium oxide nanorolls through a ligand-assisted templating method. The well-ordered nanorolls show responses similar to those seen in crystalline orthorhombic $\mathrm{V}_{2} \mathrm{O}_{5}$, while the defect-rich vanadium oxide nanorolls behave electrochemically more like sol-gel-prepared vanadium oxide materials [12]. Takahashi and co-workers prepared $\mathrm{Ni} / \mathrm{V}_{2} \mathrm{O}_{5} \cdot n \mathrm{H}_{2} \mathrm{O}$ core-shell nanocable arrays via formation of $\mathrm{Ni}$ nanorod arrays through the template based electrochemical deposition, followed by coating of $\mathrm{V}_{2} \mathrm{O}_{5} \cdot n \mathrm{H}_{2} \mathrm{O}$ on $\mathrm{Ni}$ nanorods through electrophoretic deposition. Both energy density and power density of such nanocable-array electrodes are higher than those of single-crystal $\mathrm{V}_{2} \mathrm{O}_{5}$ nanorod array and sol-gel-derived $\mathrm{V}_{2} \mathrm{O}_{5}$ film. Such significant improvement in electrochemical performance is due to the large surface area and short diffusion lengths offered by the $\mathrm{V}_{2} \mathrm{O}_{5} \cdot n \mathrm{H}_{2} \mathrm{O}$ shell [13]. Chou et al. reported $\mathrm{V}_{2} \mathrm{O}_{5}$ nanomaterials including nanoribbons, nanowires, and microflakes by an ultrasonic assisted hydrothermal method. The rechargeable Li-ion battery using $\mathrm{V}_{2} \mathrm{O}_{5}$ nanoribbons as cathode material and room temperature ionic liquid (RTIL) as electrolyte presents superior capacity, improved cyclability, good high-rate capability, and enhanced kinetics [14]. Figure 3 compared the cyclability of different $\mathrm{V}_{2} \mathrm{O}_{5}$ materials [14]. West et al. prepared manganese oxide nanowire arrays by electrodepositing into anodized alumina membranes. The nanowire arrays fabricated as cathodes offer a maximum specific capacity of $300 \mathrm{mAh} / \mathrm{g}$ [15]. Xiao et al. synthesized $\mathrm{AMoO}_{4} \cdot n \mathrm{H}_{2} \mathrm{O}(\mathrm{A}=\mathrm{Ni}$, $\mathrm{Co}$ ) nanorods by a facile hydrothermal method and presented that the dehydrated $\mathrm{AMoO}_{4}$ nanorods can be used as cathode materials for Li-ion batteries [16]. Table 1 summarizes the electrochemi- 
cal properties of 1-D nanomaterials used as active materials of Li-ion battery cathodes.

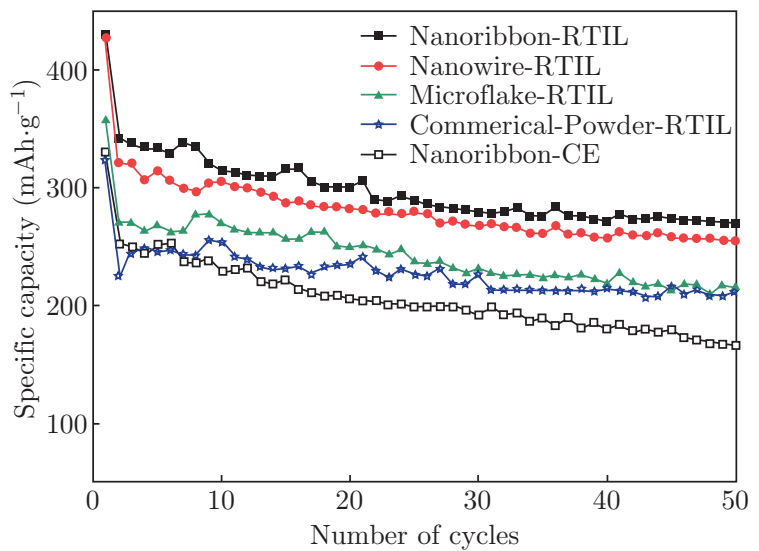

Fig. 3 Cycle life of $\mathrm{V}_{2} \mathrm{O}_{5}$ nanoribbon (solid squares), nanowire (solid circles), microflake (solid triangles), and commercial-powder (solid stars) electrode using RTIL as electrolytes; $\mathrm{V}_{2} \mathrm{O}_{5}$ nanoribbon electrode using conventional electrolytes (CE, 1 M LiPF 6 -EC/DMC (1:1, v/v), hollow square) at $25{ }^{\circ} \mathrm{C}$. Current densities are all $0.1 \mathrm{C}$ ( $C=437 \mathrm{mAh} / \mathrm{g}$ ) (from Ref. [14]).

\section{1-D Anode materials}

The main difference between anode and cathode materials is the voltage at which they reduce lithium. 1-D anode nanomaterials, in contrast to nanoparticle and thin film materials, should in principle maximize the electrode surface area while maintaining good electrical connections to the current collector [17]. Recently, there are many reports on the electrospinning polymer fibers for polymer electrolyte and the carbon or metal oxide fibers for anode materials. The fiber anode materials reveal superior physical and electrochemical properties compared with the powder materials. Yoon et al. reported carbon nanofibers of high graphitization extent prepared by a catalytic CVD process. The graphitized carbon nanofibers (CNFs) show a maximum capacity of $367 \mathrm{mAh} / \mathrm{g}$ as anode in Li-ion secondary battery [18]. Li-ion battery anodes derived from oxides of tin can store

Table 1 Electrochemical properties of 1-D nanomaterials used as active materials of Li-ion battery cathodes. (EC: ethylene carbonate, DEC: diethylene carbonate, DMC: dimethyl carbonate, PC: propylene carbonate)

\begin{tabular}{|c|c|c|c|c|c|}
\hline Material & $\begin{array}{l}\text { Electrolyte } \\
\text { solution }\end{array}$ & $\begin{array}{l}\text { Discharge } \\
\text { Capacity in } \\
\text { first cycle } \\
(\mathrm{mAh} / \mathrm{g})\end{array}$ & $\begin{array}{c}\text { Discharge } \\
\text { Capacity in } \\
n \text { cycle } \\
(\mathrm{mAh} / \mathrm{g})\end{array}$ & $\begin{array}{c}\text { Current } \\
\text { density/rate }\end{array}$ & Reference \\
\hline $\mathrm{LiCoO}_{2}$ fibers & $1 \mathrm{M} \mathrm{LiPF} 6-\mathrm{EC} / \mathrm{DEC}$ & 182 & $123(20)$ & $20 \mathrm{~mA} / \mathrm{g}$ & 6 \\
\hline $\mathrm{LiMn}_{2} \mathrm{O}_{4}$ nanowires & $1 \mathrm{M} \mathrm{LiClO}_{4}-\mathrm{EC} / \mathrm{DEC}$ & 108 & $100(100)$ & $5 \mathrm{~A} / \mathrm{g}$ & 7 \\
\hline Al-doped $\mathrm{LiMn}_{2} \mathrm{O}_{4}$ nanorods & $1 \mathrm{M} \mathrm{LiPF} 6-\mathrm{EC} / \mathrm{DEC}$ & 100 & $96(100)$ & $1 \mathrm{C}$ & 8 \\
\hline $\begin{array}{l}\mathrm{VGCF} / \mathrm{LiFePO}_{4} / \mathrm{C} \\
\text { core-shell nanowire }\end{array}$ & $1 \mathrm{M} \mathrm{LiClO}_{4}-\mathrm{EC} / \mathrm{DEC}$ & 160 & $160(20)$ & $0.01 \mathrm{~A} / \mathrm{g}$ & 10 \\
\hline $\begin{array}{l}\mathrm{LiFePO}_{4} \\
\text { nanothumb/MWCNTs }\end{array}$ & $1 \mathrm{M} \mathrm{LiPF}_{6}-\mathrm{EC} / \mathrm{DEC}$ & 128 & - & $10 \mathrm{C}$ & 11 \\
\hline vanadium oxide nanorolls & $1 \mathrm{M} \mathrm{LiClO}_{4}-\mathrm{EC} / \mathrm{DMC}$ & $240-340$ & - & $60 \mathrm{~mA} / \mathrm{g}$ & 12 \\
\hline $\begin{array}{l}\mathrm{Ni} / \mathrm{V}_{2} \mathrm{O}_{5} \cdot n \mathrm{H}_{2} \mathrm{O} \\
\text { core-shell nanocable arrays }\end{array}$ & $1 \mathrm{M} \mathrm{LiClO}_{4}-\mathrm{PC}$ & 465 & - & $1.6 \mathrm{~A} / \mathrm{g}$ & 13 \\
\hline $\mathrm{V}_{2} \mathrm{O}_{5}$ nanoribbons & $1 \mathrm{M} \operatorname{LiNTf}_{2-}\left[\mathrm{C}_{3} \mathrm{mpyr}\right]\left[\mathrm{NTf}_{2}\right]$ & 430 & $270(50)$ & $0.1 \mathrm{C}$ & 14 \\
\hline manganese oxide nanowire arrays & $1 \mathrm{M} \mathrm{LiPF} 6-\mathrm{PC}$ & 300 & - & $37.6 \mu \mathrm{A} /\left(\mathrm{cm}^{2}\right)$ & 15 \\
\hline $\mathrm{NiMoO}_{4}$ nanorods & $1 \mathrm{M} \mathrm{LiPF}_{6}-\mathrm{EC} / \mathrm{DEC}$ & 275 & $100(70)$ & $50 \mathrm{~mA} / \mathrm{g}$ & 16 \\
\hline
\end{tabular}

over twice as much $\mathrm{Li}^{+}$as graphite. However, when $\mathrm{Li}^{+}$is inserted and removed from these Snbased materials, large volume changes occur, and this causes internal damage resulting in loss of capacity and rechargability. Li et al. fabriated a Li-ion battery anode consist of monodisperse $\mathrm{SnO}_{2}$ nanofibers protruding from a current-collector surface via the template method. The dramatically- improved rate and cycling performance of the electrode is related to the small size of the nanofibers [19]. Park et al. synthesized $\mathrm{SnO}_{2}$ nanowires with tetragonal structure by a thermal evaporation method without metal catalysts. The $\mathrm{SnO}_{2}$ nanowires show improved specific capacity for lithium insertion as compared to nanoparticle anodes [20]. 
As a new class of anode materials for Li-ion batteries, transition metal oxides can in principle deliver as high as three times the capacity of currently used graphite $(<372 \mathrm{mAh} / \mathrm{g})$ [21]. However, they usually suffer from poor capacity retention upon cycling and poor rate capability, partly attributed to the large volume changes during repeated lithium uptake and removal reactions. Armstrong et al. reported the $\mathrm{TiO}_{2}-\mathrm{B}$ nanotubes or wires (a polymorph of titania with a more open lattice structure than anatase and rutile) as anodes in both liquid and polymer electrolyte cells. The 1-D $\mathrm{TiO}_{2}-\mathrm{B}$ polymorph can reduce $\mathrm{Li}^{+}$at a much higher potential than lithium metal, with excellent capacity retention on cycling and a superior rate capability to nanoparticulate anatase and bulk $\mathrm{TiO}_{2}$-B [22]. Lou et al. used a one-step self-supported topotactic transformation approach to synthesize $\mathrm{Co}_{3} \mathrm{O}_{4}$ needlelike nanotubes. As anode active material, $\mathrm{Co}_{3} \mathrm{O}_{4}$ nanotubes show manifest ultrahigh Li storage capacity with improved cycle life and high rate capability [23]. Taberna et al. reported the electrochemically assisted template growth of vertically aligned $\mathrm{Cu}$ nanorod arrays which used as supports for electrochemical plated polycrystalline $\mathrm{Fe}_{3} \mathrm{O}_{4}$ shells. Such $\mathrm{Fe}_{3} \mathrm{O}_{4^{-}}$ based $\mathrm{Cu}$ nanorod arrays as anodes display a factor of six improvement in power density over the
$\mathrm{Fe}_{3} \mathrm{O}_{4}$-based $\mathrm{Cu}$ planar electrodes while maintaining the same total discharge time [24].

Silicon is an attractive anode material for $\mathrm{Li}$ ion batteries because it has a low discharge potential and the highest known theoretical charge capacity (4200 mAh/g). However silicon's volume changes by $400 \%$ upon insertion and extraction of lithium which causes pulverization of silicon materials and capacity fading. Chan et al. reported vapor-liquid-solid (VLS) grown silicon nanowires on a stainless steel current collector which can accommodate large strain without pulverization. The silicon anodes show the theoretical charge capacity and maintain a discharge capacity close to $75 \%$ of this maximum, with little fading during cycling [25]. Designing nanoscale hierarchical structures is another approach to address the issues associated with the large volume changes. Cui and co-workers prepared crystalline silicon/amorphous silicon (a-Si) core-shell nanowire and CNFs/a-Si core-shell nanowires grown by the VLS mechanism for anodes. Due to the difference of their lithiation potentials, the a-Si shells store $\mathrm{Li}^{+}$ions, and the crystalline $\mathrm{Si}$ or CNFs core serves as a stable mechanical support and efficient electrical conducting pathway [26]. Table 2 summarizes the electrochemical properties of 1-D nanomaterials used as active materials of Li-ion battery anodes.

Table 2 Electrochemical properties of 1-D nanomaterials used as active materials of Li-ion battery anodes. (GPE: gel-polymer electrolyte)

\begin{tabular}{|c|c|c|c|c|c|c|}
\hline Material & $\begin{array}{l}\text { Electrolyte } \\
\text { solution }\end{array}$ & $\begin{array}{l}\text { Discharge } \\
\text { Capacity in } \\
\text { first cycle } \\
(\mathrm{mAh} / \mathrm{g})\end{array}$ & $\begin{array}{l}\text { Coulombic } \\
\text { efficiency in } \\
\text { first cycle }\end{array}$ & $\begin{array}{c}\text { Discharge } \\
\text { Capacity in } \\
n \text { cycle } \\
(\mathrm{mAh} / \mathrm{g})\end{array}$ & $\begin{array}{c}\text { Current } \\
\text { density/rate }\end{array}$ & Reference \\
\hline graphitized CNFs & $1 \mathrm{M} \mathrm{LiClO}_{4}-\mathrm{EC} / \mathrm{DEC}$ & 367 & $69 \%$ & - & $30 \mathrm{~mA} / \mathrm{g}$ & 18 \\
\hline $\mathrm{SnO}_{2}$ nanofibers & $1 \mathrm{M} \mathrm{LiClO}_{4}-\mathrm{EC} / \mathrm{DEC}$ & $>700$ & $97 \%$ & - & $0.32 \mathrm{~mA} /\left(\mathrm{cm}^{2}\right)$ & 19 \\
\hline $\mathrm{SnO}_{2}$ nanowires & $1 \mathrm{M} \mathrm{LiPF} 6-\mathrm{EC} / \mathrm{DMC}$ & 1134 & $31.01 \%$ & $300(50)$ & $100 \mathrm{~mA} / \mathrm{g}$ & 20 \\
\hline $\mathrm{TiO}_{2}-\mathrm{B}$ nanowires & $\mathrm{GPE}\left(\mathrm{LiPF}_{6} / \mathrm{EC} / \mathrm{PC}-\mathrm{PVdF}\right)$ & 225 & - & - & $\mathrm{C} / 5$ & 22 \\
\hline $\mathrm{Co}_{3} \mathrm{O}_{4}$ nanotubes & $1 \mathrm{M} \mathrm{LiPF} 6-\mathrm{EC} / \mathrm{DEC}$ & 950 & - & $918(30)$ & $50 \mathrm{~mA} / \mathrm{g}$ & 23 \\
\hline Si nanowire & - & 3124 & $73 \%$ & - & $\mathrm{C} / 20$ & 25 \\
\hline $\begin{array}{l}\mathrm{CNF} / \mathrm{a}-\mathrm{Si} \\
\text { core-shell nanowires }\end{array}$ & - & 2000 & $90 \%$ & $1300(47)$ & $\mathrm{C} / 5$ & 26 \\
\hline
\end{tabular}

\section{Application of 1-D nanomaterials in su- percapacitor}

Supercapacitor, also called electrochemical capacitor, golden capacitor or ultracapacitor, is a new type of energy storage device that has seen great improvement in recent years. Since 1978, when NEC first introduced the trade name Supercapacitor ${ }^{T M}$, the technology has evolved from first generation products with low energy 
density for memory protection applications to create megajoule-size capacitors for transportation and power quality applications [1]. There are two general categories of supercapacitors: electric double-layer capacitors (EDLC) and electrochemical pseudocapacitors (EPCs). The capacitance of EDLCs is based on charge separation at the electrode/electrolyte interface, whereas the capacitance of EPCs arises from fast and reversible faradic redox reactions occurring within the electroactive materials [2]. Figure 4 is a schematic illustration of the supercapacitor.

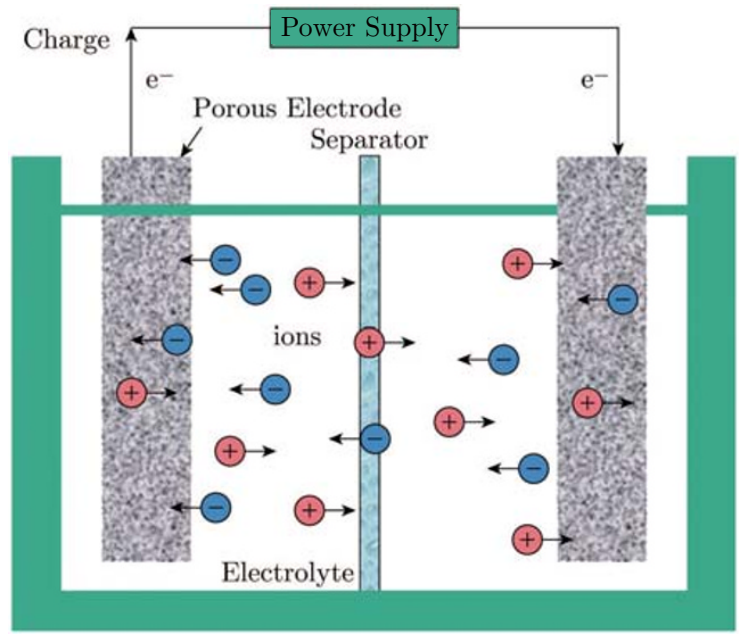

Fig. 4 Schematic illustration of a supercapacitor.

\section{1-D carbon materials}

1-D carbon materials, such as carbon nanotubes (CNTs), are widely used for supercapacitor electrode materials because of their unique morphology, exceptional electrical conductivity, mechanical properties and versatile existing forms [27,28]. In 1997, Niu et al. prepared an entangled-CNT sheet electrode from catalytically grown CNTs of narrow diameter distribution $(\sim 8 \mathrm{~nm})$ for high power performance EDLCs $(>8 \mathrm{~kW} / \mathrm{kg})$ [29]. An et al. reported a single-walled carbon nanotube (SWCNT)/Ni foam electrode with small equivalent series resistance (ESR) and improved power density [30]. The specific capacitance of the CNT electrodes is not very high because of their low specific surface area compared to activated carbon. Wang et al. fabricated a carbon cloth electrode deposited with partially-exfoliated MWCNTs. The enhanced capacitance (in a range of $130-165 \mathrm{~F} / \mathrm{g}$ at $5-0.5 \mathrm{~A} / \mathrm{g}$ ) comparable to graphene could be attributed to improved effective surface area and increased defect density of the exfoliated tubular structure [31]. Usually, vertically aligned CNT arrays (CNTA) are grown either by using thin catalyst layers predeposited on substrates or through vapour-phase catalyst delivery. Using the latter method, Talapatra et al. reported CNTA grown on Inconel 600 (a metallic alloy). The CNTA/Inconel 600 electrode for EDLCs showed lower contact resistance and higher rate capability over previously designed CNT electrodes [32].

\section{1-D Transition metal oxides}

Pseudo-capacitive materials, which bulk undergoes a fast redox reaction to provide the capacitive response, exhibit superior specific energies to the carbon-based supercapacitor materials. The commercial application of $\mathrm{RuO}_{2}$ is limited by its high cost and toxicity. Alternative transition metal oxides are attractive in view of their low cost and excellent capacitive performance in the aqueous electrolytes. Wang et al. synthesized $\mathrm{MnO}_{2}$ nanowires and microrods through a simply hydrothermal route. The $\mathrm{MnO}_{2}$ microrods show better capacitive performance than other $\mathrm{MnO}_{2}$ materials they obtained [33]. Tang et al. reported manganese oxide nanobelt bundles with layered structure by hydrothermally treating K-type layered manganese oxide precursor. The manganese oxide nanobelt bundles display good capacitive behavior with a specific capacitance of $268 \mathrm{~F} / \mathrm{g}$ and cycling stability in a neutral electrolyte system [34]. $\mathrm{Xu}$ et al. synthesized $\mathrm{Co}_{3} \mathrm{O}_{4}$ nanotubes by chemically depositing cobalt hydroxide in anodic aluminum oxide (AAO) templates and thermally annealing at $500^{\circ} \mathrm{C}$. The $\mathrm{Co}_{3} \mathrm{O}_{4}$ nanotubes exhibit good capacitive behavior with a specific capacitance of $574 \mathrm{~F} / \mathrm{g}$ at a current density of $0.1 \mathrm{~A} / \mathrm{g}$ and good specific capacitance retention [35]. Rajeswari et al. prepared $\mathrm{MoO}_{2}$ nanorods by thermal decomposition of tetrabutylammonium hexamolybdate $\left(\left[\left(\mathrm{C}_{4} \mathrm{H}_{9}\right)_{4} \mathrm{~N}\right]_{2} \mathrm{Mo}_{6} \mathrm{O}_{19}\right)$ in an inert atmosphere. The $\mathrm{MoO}_{2}$ nanorods show good capacitive behaviour with a specific capacitance of $140 \mathrm{~F} / \mathrm{g}[36]$.

\section{1-D carbon material composites}

Another group of interesting materials for supercapacitors described in this review are 1-D car- 
bon material composites. Takamura et al. modified the surface of activated CNFs by coating the thin film of the oxides of $\mathrm{Ag}, \mathrm{Cu}, \mathrm{Pd}$, and $\mathrm{Sn}$. The transition metal oxides effectively enhance the capacitance and high rate charge/discharge performance of the composites which might be used as negative electrode materials for Li-ion hybrid supercapacitor [37]. Ye et al. prepared a $\mathrm{RuO}_{2} / \mathrm{MWCNT}$ electrode by magnetic-sputtering $\mathrm{Ru}$ in $\mathrm{Ar} / \mathrm{O}_{2}$ atmosphere onto CVD-synthesized MWCNTs. The capacitance of the MWCNT electrodes is significantly increased from 0.35 to $16.94 \mathrm{mF} /\left(\mathrm{cm}^{2}\right)$ by modification with $\mathrm{RuO}_{2}$ [38]. On the other hand, it appears that CNTs is a perfect conducting additive and/or support for inexpensive transition metal oxides of poor electrical conductivity. Raymundo-Piñero et al. prepared a $\alpha-\mathrm{MnO}_{2} \cdot n \mathrm{H}_{2} \mathrm{O} / \mathrm{MWCNT}$ nanocomposite by chemical co-precipitation of $\mathrm{Mn}^{7+}$ and $\mathrm{Mn}^{2+}$ in water medium which contained a predetermined amount of MWCNTs. The $\alpha-\mathrm{MnO}_{2} / \mathrm{MWCNT}$ electrode shows an improved specific capacitance of $140 \mathrm{~F} / \mathrm{g}$ with good cyclability and high dynamic of charge propagation [39]. Cui et al. designed a $\mathrm{Mn}_{3} \mathrm{O}_{4} / \mathrm{CNTA}$ composite electrode by dip-casting method for high performance arealimited supercapacitor. The maximum specific capacitance of the $\mathrm{Mn}_{3} \mathrm{O}_{4} / \mathrm{CNTA}$ composite electrode is found to be $143 \mathrm{~F} / \mathrm{g}$ while the specific capacitance for as-grown CNTA electrode is only 1-2 F/g [40]. Zhang et al. reported manganese oxide nanoflower/CNTA/Ta foil composite electrodes prepared by combining CVD method and potentiodynamic electrodeposition technique [41]. Fan et al. prepared a $\gamma-\mathrm{MnO}_{2} / \mathrm{ACNT} /$ graphite substrate composite electrode by combining CVD method and electrochemically induced deposition technology [42]. Recently, we fabricated a $\mathrm{MnO}_{x} / \mathrm{MWCNT} / \mathrm{Ni}$ foam composite electrode by combining CVD method and cathodic electrodeposition technique. Figure 5 showed TEM images of individual $\mathrm{MnO}_{x} / \mathrm{CNT}$ composites with different magnifications [43]. These binder-free supercapacitor electrodes display low ESR, excellent power characteristics, high specific capacitance, and superior long-term cycle stability.

\section{1-D polymers and their composites}

Conducting polymers, namely, polyaniline (PAni),

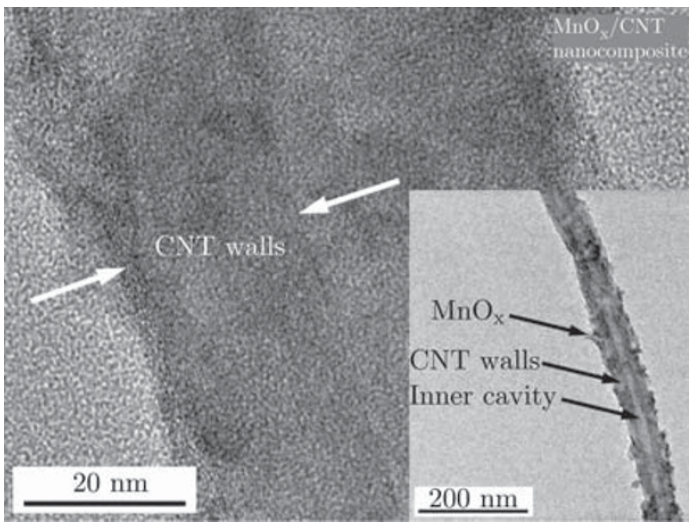

Fig. 5 TEM images of individual $\mathrm{MnO}_{x} / \mathrm{CNT}$ composites with low (inset) and high magnification (from Ref. [43]).

polypyrrole (PPy), polythiophene (PTh) and poly (3,4-ethylenedioxythiophene) (PEDOT), are pseudo-capacitive materials [44]. In general, conducting polymers have greater power capability than the inorganic battery materials but poor cycle-life compared with carbon-based materials. Supercapacitor electrodes that utilise 1-D conducting polymers materials as well as composites with CNTs and inorganic battery materials are attractive because of their high power capability and improved specific energy density. Kim et al. reported the Polyacrylonitrile (PAN)-based activated $\mathrm{CNF}$ web as electrode material for EDLC. PAN solutions in dimethylformamide (DMF) were electrospun into webs consisting of $300 \mathrm{~nm}$ ultrafine fibers, and then activated to prepare highsurface area PAN-based activated CNF webs. The PAN-based activated CNF webs activated at $800^{\circ} \mathrm{C}$ with steam for $60 \mathrm{~min}$ exhibit the highest specific capacitance of $134 \mathrm{~F} / \mathrm{g}$ [45]. Niu et al. prepared polyvinylpyrrolidone (PVP)/PAN blend nanofibers by conventional electrospinning and PVP/PAN side-by-side bicomponent nanofibers by bicomponent electrospinning. The CNFs produced from the side-by-side polymer nanofibers by a direct pyrolysis treatment show better fiberinterconnections and carbon crystalline structure and higher electrochemical capacitance than those from the polymer blend nanofibers [46]. Guan et al. reported PAni nanofibers by interfacial polymerization in the presence of paraphenylenediamine (PPD) for high-rate supercapacitors. The PAni nanofibers display a specific capacitance value of $548 \mathrm{~F} / \mathrm{g}$, a specific power value of $0.127 \mathrm{~kW} / \mathrm{kg}$ and a specific energy value of $36 \mathrm{Wh} / \mathrm{kg}$ at a constant discharge current den- 
sity of $0.18 \mathrm{~A} / \mathrm{g}$ [47]. Khomenko et al. fabricated an asymmetric capacitor with PPy/MWCNTs as negative electrode and PAni/MWCNTs as positive electrode, giving specific capacitance values of $200 \mathrm{~F} / \mathrm{g}$ for PPy/MWCNTs and $360 \mathrm{~F} / \mathrm{g}$ for PAni/MWCNTs, respectively. The well conducting properties and available mesoporosity of MWCNTs allow good charge propagation in the composites [48]. Mujawar et al. investigated facile growth of vertically aligned PAni nanotubes on a titanium nanotube (TNT) template using electrochemical polymerization and obtained a specific capacitance value of $740 \mathrm{~F} / \mathrm{g}$ at charge discharge rate of $3 \mathrm{~A} / \mathrm{g}$ [49]. Table 3 summarizes the electrochemical properties of 1-D nanomaterials application for supercapacitor electrodes.

Table 3 Electrochemical properties of 1-D nanomaterials application for supercapacitor electrodes.

\begin{tabular}{|c|c|c|c|c|c|c|}
\hline Material & $\begin{array}{l}\text { Electrolyte } \\
\text { solution }\end{array}$ & $\begin{array}{l}\text { Maximum } \\
\text { specific } \\
\text { capacitance }\end{array}$ & $\begin{array}{c}\text { Current } \\
\text { density/ } \\
\text { sweep rate }\end{array}$ & $\begin{array}{c}\text { Power } \\
\text { density } \\
(\mathrm{kW} / \mathrm{kg})\end{array}$ & $\begin{array}{c}\text { Electric } \\
\text { resistance } \\
(\Omega)\end{array}$ & Reference \\
\hline PAN-based CNFs & $6 \mathrm{M} \mathrm{KOH}$ & $134 \mathrm{~F} / \mathrm{g}$ & $1 \mathrm{~mA} /\left(\mathrm{cm}^{2}\right)$ & - & - & 45 \\
\hline MWCNTs & $38 \mathrm{wt} \% \mathrm{H}_{2} \mathrm{SO}_{4}$ & $104 \mathrm{~F} / \mathrm{g}$ & - & $>8$ & $0.094 \Omega(\mathrm{ESR})$ & 29 \\
\hline SWCNTs & $7.5 \mathrm{~N} \mathrm{KOH}$ & $180 \mathrm{~F} / \mathrm{g}$ & $1 \mathrm{~mA} /\left(\mathrm{cm}^{2}\right)$ & 20 & $52 \mathrm{~m} \Omega(\mathrm{ESR})$ & 30 \\
\hline exfoliated MWCNTs & $3 \mathrm{M} \mathrm{NaOH}$ & $165 \mathrm{~F} / \mathrm{g}$ & $0.5 \mathrm{~A} / \mathrm{g}$ & - & - & 31 \\
\hline CNTA & $6 \mathrm{M} \mathrm{NaOH}$ & $18 \mathrm{~F} / \mathrm{g}$ & $2 \mathrm{~mA}$ & 7 & - & 32 \\
\hline $\begin{array}{c}\text { manganese } \\
\text { oxide nanobelts }\end{array}$ & $1 \mathrm{M} \mathrm{Na} 2 \mathrm{SO}_{4}$ & $268 \mathrm{~F} / \mathrm{g}$ & $5 \mathrm{mV} / \mathrm{s}$ & - & - & 34 \\
\hline $\mathrm{Co}_{3} \mathrm{O}_{4}$ nanotubes & $6 \mathrm{M} \mathrm{KOH}$ & $574 \mathrm{~F} / \mathrm{g}$ & $0.1 \mathrm{~A} / \mathrm{g}$ & - & $0.4 \Omega$ & 35 \\
\hline $\mathrm{MoO}_{2}$ nanorods & $1 \mathrm{M} \mathrm{H}_{2} \mathrm{SO}_{4}$ & $140 \mathrm{~F} / \mathrm{g}$ & $1 \mathrm{~mA} /\left(\mathrm{cm}^{2}\right)$ & - & - & 36 \\
\hline PAni nanofibers & $1 \mathrm{M} \mathrm{H}_{2} \mathrm{SO}_{4}$ & $548 \mathrm{~F} / \mathrm{g}$ & $0.18 \mathrm{~A} / \mathrm{g}$ & 0.127 & $0.76 \Omega$ & 47 \\
\hline $\mathrm{RuO}_{2} / \mathrm{MWCNT}$ & $1 \mathrm{M} \mathrm{H}_{2} \mathrm{SO}_{4}$ & $16.94 \mathrm{mF} /\left(\mathrm{cm}^{2}\right)$ & $0.2 \mathrm{~mA}$ & - & - & 38 \\
\hline $\begin{array}{c}\mathrm{A}-\mathrm{MnO}_{2} \cdot n \mathrm{H}_{2} \mathrm{O} / \\
\mathrm{MWCNT}\end{array}$ & $1 \mathrm{M} \mathrm{Na} 2 \mathrm{SO}_{4}$ & $141 \mathrm{~F} / \mathrm{g}$ & $2 \mathrm{mV} / \mathrm{s}$ & - & $3.5 \Omega /\left(\mathrm{cm}^{2}\right)$ & 39 \\
\hline $\begin{array}{c}\text { manganese } \\
\text { oxide/CNTA }\end{array}$ & - & $144 \mathrm{~F} / \mathrm{g}$ & $500 \mathrm{~A} / \mathrm{g}$ & - & $1.66 \Omega(\mathrm{ESR})$ & 41 \\
\hline PAni/MWCNTs & $1 \mathrm{M} \mathrm{H}_{2} \mathrm{SO}_{4}$ & $360 \mathrm{~F} / \mathrm{g}$ & $2 \mathrm{~mA}$ & - & $0.48 \Omega /\left(\mathrm{cm}^{2}\right)$ & \\
\hline PPy/MWCNTs & & $200 \mathrm{~F} / \mathrm{g}$ & & & $0.86 \Omega /\left(\mathrm{cm}^{2}\right)$ & 48 \\
\hline PAni nanotube/TNT & $1 \mathrm{M} \mathrm{H}_{2} \mathrm{SO}_{4}$ & $740 \mathrm{~F} / \mathrm{g}$ & $3 \mathrm{~A} / \mathrm{g}$ & 3 & - & 49 \\
\hline
\end{tabular}

\section{Conclusion}

The proliferation of personal electronics and commercialization of electric and hybrid electric vehicles has popularized the need for rechargeable Li-ion batteries. Supercapacitors are crucial in supporting the voltage of a system during increased loads. To develop advanced energy conversion and storage devices, active electrode materials with superior electrochemical performance are essential. Moving from bulk materials to the nanoscale can significantly change electrode and electrolyte properties, and consequently their electrochemical performance. In particular, 1-D nanomaterials have demonstrated significant improvements over conventional electrode materials with superior specific capacities, higher rate capabilities, better cycling performances. In the future, much attention should be devoted to new, lowcost and environmentally friendly 1-D nanomate- rials obtained by facile preparation processes.

\section{Acknowledgements}

The project was supported by the National Natural Science Foundation of China (No. 50730008, 09ZR1414800), Science and Technology Commission of Shanghai Municipality, China (No. 1052nm02000 and 09JC1407400), Shanghai Research Fund for the Post-doctoral Program (No. 10R21414700) and China Postdoctoral Science Foundation funded project (No. 20100470710).

\section{References}

[1] R. J. Brodd, K. R. Bullock, R. A. Leising, R. L. Middaugh, J. R. Miller and E. Takeuchi, J. Electrochem. Soc. 151, K1 (2004). http://dx.doi.org/10.1149/1. 1641042 
[2] B. E. Conway, Electrochemical SupercapacitorsScientific Fundamentals and Technological Applications, Kluwer Academic/Plenum, New York (1999).

[3] A. S. Aricò, P. Bruce, B. Scrosati, J.-M. Tarascon and W. Schalkwijk, Nat. Mater. 4, 366 (2005). http://dx. doi.org/10.1038/nmat1368

[4] L. Y. Zhang, J. Wang, L. M. Wei, P. Liu, H. Wei and Y. F. Zhang, Nano-Micro Lett. 1, 49 (2009). http:// dx.doi.org/10.5101/nml.v1i1.p49-52

[5] Z. J. Li, L. Wang, Y. J. Su, P. Liu and Y. F. Zhang, Nano-Micro Lett. 1, 9 (2009). http://dx.doi.org/ 10.5101/nml.v1i1.p9-13

[6] Y. X. Gu, D. R. Chen and X. L. Jiao, J. Phys. Chem. B 109 (38), 17901 (2005). http://dx.doi.org/10.1021/ jp0521813

[7] E. Hosono, T. Kudo, I. Honma, H. Matsuda and H. S. Zhou, Nano Lett. 9 (3), 1045 (2009). http://dx.doi. org/10.1021/nl803394v

[8] Y. Yang, C. Xie, R. Ruffo, H. Peng, D. K. Kim and Y. Cui, Nano Lett. 9 (12), 4109 (2009). http://dx.doi. org/10.1021/n1902315u

[9] A. K. Padhi, K. S. Nanjundaswamy, C. Masquelier, S. Okada and J. B. Goodenough, J. Electrochem. Soc. 144 (5), 1609 (1997). http://dx.doi.org/10.1149/1. 1837649

[10] E. Hosono, Y. G. Wang, N. Kida, M. Enomoto, N. Kojima, M. Okubo, H. Matsuda, Y. Saito, T. Kudo, I. Honma and H. S. Zhou, Appl. Mater. Interfaces 2 (1), 212 (2010). http://dx.doi.org/10.1021/am900656y

[11] A. V. Murugan, T. Muraliganth, P. J. Ferreira and A. Manthiram, Inorg. Chem. 48 (3), 946 (2009). http:// dx.doi .org/10.1021/ic8015723

[12] D. Sun, C. W. Kwon, G. Baure, E. Richman, J. MacLean, B. Dunn and S. H. Tolbert, Adv. Funct. Mater. 14 (12),1197 (2004).http://dx.doi.org/10. 1002/adfm. 200400056

[13] K. Takahashi, Y. Wang and G. Cao, J. Phys. Chem. B 109 (1), 48 (2005). http://dx.doi.org/10.1021/ jp044772j

[14] S. L. Chou, J. Z. Wang, J. Z. Sun, D. Wexler, M. Forsyth, H. K. Liu, D. R. MacFarlane and S. X. Dou, Chem. Mater. 20 (22), 7044 (2008). http://dx.doi. org/10.1021/cm801468q

[15] W. C. West, N. V. Myung, J. F. Whitacre and B. V. Ratnakumar, J. Power Sources 126 (1-2), 203 (2004). http://dx.doi.org/10.1016/j. jpowsour. 2003.08.020

[16] W. Xiao, J. S. Chen, C. M. Li, R. Xu and X. W. Lou, Chem. Mater. 22 (3), 746 (2010). http://dx. doi.org/10.1021/cm9012014

[17] A. I. Hochbaum and P. Yang, Chem. Rev. 110 (1), 527 (2010). http://dx.doi.org/10.1021/cr900075v

[18] S. H. Yoon, C. W. Park, H. Yang, Y. Korai, I. Mochida, R. T. K. Baker and N. M. Rodriguez, Carbon 42 (1), 21 (2004). http://dx.doi.org/10.1016/ j.carbon. 2003.09.021

[19] N. Li, C. R. Martin and B. Scrosati, J. Power Sources 97, 240 (2001). http://dx.doi.org/10.1016/ S0378-7753(01) 00760-1
[20] M. S. Park, G. X. Wang, Y. M. Kang, D. Wexler, S. X. Dou and H. K. Liu, Angew. Chem. Int. Ed. 46 (5), 750 (2007). http://dx.doi.org/10.1002/anie. 200603309

[21] P. Poizot, S. Laruelle, S. Grugeon, L. Dupont and J. M. Tarascon, Nature 407, 496 (2000). http://dx.doi. org/10.1038/35035045

[22] G. Armstrong, A. R. Armstrong, P. G. Bruce, P. Reale and B. Scrosati, Adv. Mater. 18 (19), 2597 (2006). http://dx.doi.org/10.1002/adma. 200601232

[23] X. W. Lou, D. Deng, J. Y. Lee, J. Feng and L. A. Archer, Adv. Mater. 20 (2), 258 (2008). http://dx. doi .org/10.1002/adma. 200702412

[24] P. L. Taberna, S. Mitra, P. Poizot, P. Simon and J. M. Tarascon, Nat. Mater. 5, 567 (2006). http://dx. doi.org/10.1038/nmat1672

[25] C. K. Chan, H. Peng, G. Liu, K. McIlwrath, X. F. Zhang, R. A. Huggins and Y. Cui, Nat. Nanotechnol. 3 (1), 31 (2008). http://dx.doi.org/10.1038/nnano. 2007.411

[26] L. F. Cui, Y. Yang, C. M. Hsu and Y. Cui, Nano Lett. 9 (9), 3370 (2009). http://dx.doi.org/10. 1021/n1901670t

[27] E. Frackowiak, Phys. Chem. Chem. Phys. 9, 1774 (2007). http://dx.doi.org/10.1039/b618139m

[28] M. Inagaki, H. Konno, O. Tanaike, J. Power Sources 195, 7880 (2010). http://dx.doi.org/10.1016/j. jpowsour.2010.06.036

[29] C. Niu, E. K. Sichel, R. Hoch, D. Moy and H. Tennent, Appl. Phys. Lett. 70 (11), 1480 (1997). http:// dx.doi.org/10.1063/1.118568

[30] K. H. An, W. S. Kim, Y. S. Park, Y. C. Choi, S. M. Lee, D. C. Chung, D. J. Bae, S. C. Lim and Y. H. Lee, Adv. Mater. 13 (7), 497 (2001). http://dx. doi.org/10.1002/1521-4095(200104)13: $7 \$<497:$ : AID-ADMA497\$>\$3. 0. CO;2-H

[31] G. Wang, Y. Ling, F. Qian, X. Yang, X. X. Liu and Y. Li, J. Power Sources 196 (11), 5209 (2011). http:// dx.doi.org/10.1016/j.jpowsour. 2011.02.019

[32] S. Talapatra, S. Kar, S. K. Pal, R. Vajtai, L. Ci, P. Victor, M. M. Shaijumon, S. Kaur, O. Nalamasu and P. M. Ajayan, Nat. Nanotechnol. 1, 112 (2006). http:// dx.doi.org/10.1038/nnano. 2006.56

[33] N. Wang, H. Pang, H. Peng, G. Li and X. Chen, Cryst. Res. Technol. 44 (11), 1230 (2009). http://dx.doi. org/10.1002/crat. 200800619

[34] X. Tang, H. Li, Z. H. Liu, Z. Yang and Z. Wang, J. Power Sources 196, 855 (2011). http://dx.doi.org/ 10.1016/j.jpowsour. 2010.06.067

[35] J. Xu, L. Gao, J. Cao, W. Wang and Z. Chen, Electrochim. Acta, 56, 732 (2010). http://dx.doi.org/ 10.1016/j.electacta.2010.09.092

[36] J. Rajeswari, P. S. Kishore, B. Viswanathan and T. K. Varadarajan, Electrochem. Commun. 11, 572 (2009). http://dx.doi.org/10.1016/j.elecom. 2008.12.050

[37] T. Takamura, Y. Sato and Y. Sato, J. Power Sources (2011), in press. http://dx.doi.org/10. 1016/j · jpowsour. 2011.02 .041 
[38] J. S. Ye, H. F. Cui, X. Liu, T. M. Lim, W. D. Zhang and F. S. Sheu, Small 1 (5), 560 (2005). http://dx. doi.org/10.1002/smll. 200400137

[39] E. Raymundo-Piñero, V. Khomenko, E. Frackowiak and F. Béguin, J. Electrochem. Soc. 152 (1), A229 (2005). http://dx.doi.org/10.1149/1.1834913

[40] X. Cui, F. Hu, W. Wei and W. Chen, Carbon 49, 1225 (2011). http://dx.doi.org/10.1016/j.carbon. 2010.11 .039

[41] H. Zhang, G. Cao, Z. Wang, Y. Yang, Z. Shi and Z. Gu, Nano Lett. 8 (9), 2664 (2008). http://dx.doi. org/10.1021/nl800925j

[42] Z. Fan, J. Chen, B. Zhang, B. Liu, X. Zhong and Y. Kuang, Diamond Relat. Mater. 17, 1943 (2008). http://dx.doi.org/10.1016/j.diamond.2008.04. 015

[43] D. Zhao, Z. Yang, L. Zhang, X. Feng and Y. Zhang, Electrochem. Solid-State Lett. 14 (6) A93 (2011). http://dx.doi.org/10.1149/1.3562927
[44] G. A. Snook, P. Kao and A. S. Best, J. Power Sources 196, 1 (2011). http://dx.doi.org/10.1016/ j. jpowsour . 2010.06.084

[45] C. Kim, K. S. Yang and W. J. Lee, Electrochem. SolidState Lett. 7 (11), A397 (2004). http://dx.doi.org/ 10.1149/1.1801631

[46] H. Niu, J. Zhang, Z. Xie, X. Wang and T. Lin, Carbon 49 (7), 2380 (2011). http://dx.doi.org/10.1016/j. carbon.2011.02.005

[47] H. Guan, L. Z. Fan, H. Zhang and X. Qu, Electrochim. Acta 56 (2), 964 (2010). http://dx.doi. org/10.1016/j.electacta.2010.09.078

[48] V. Khomenko, E. Frackowiak and F. Béguin, Electrochim. Acta 50 (12), 2499 (2005). http://dx.doi. org/10.1016/j.electacta. 2004.10.078

[49] S. H. Mujawar, S. B. Ambade, T. Battumur, R. B. Ambade and S. H. Lee, Electrochim. Acta (2011), in press. http://dx.doi.org/10.1016/j.electacta. 2011.02 .043 